\title{
A Escola e o Museu de Arte
}

\section{Roseane Martins Coetho}

Este artigo é um relato da experiência de uma pesquisa-ação cultural em desenvolvimento pelo Museu de Arte de Santa Catarina- MASC com três escolas públicas de Florianópolis.

Trata-se da apresentação do projeto, seus pressupostos metodológicos e alguns resultados, ainda que parciais, uma vez que é um projeto que está em andamento.

O Museu de Arte de Santa Catarina, através do Núcleo de Arte-Educação, vem desenvolvendo a partir de julho de 2000, o projeto "O MUSEU E A ESCOLA" . Este projeto nasce da constatação das arte-educadoras do museu, de que a grande maioria das escolas que agendam visitas monitoradas oferecidas pelo museu, o fazem com pouca regularidade, sem preparação prévia, e na maior parte das vezes, a professora, junto com a turma toma conhecimento na hora do conteúdo exposto, e sendo assim, não costumam relacionar o conteúdo da exposição com os desenvolvidos em seu programa de trabalho, ou, se o fazem, é de modo assistemático.

Sendo assim, trabalho do museu, em termos educacionais, resultava em receber escolas, monitorar as visitas e quantificar o atendimento, mesmo que tivesse a constante preocupação com a qualidade deste atendimento. Por outro lado, as escolas que frequentavam o MASC o faziam muito no espírito de "visitação", entendendo que a compreeensão da arte e seu potencial educativo, como amplitude da leitura do mundo, é função e objetivo da educação em arte, tanto nas instituições formais - as escolas, como nas instituições informais - no caso, o museu de arte, - é que este projeto piloto de pesquisa- ação cultural está sendo 
desenvolvido, desde que foi agraciado com o apoio da Fundação Vitae, no seu Programa de Apoio a Museus.

Fica aqui registrado que sem este apoio o Projeto não seria desenvolvido, já que nos proporcionou a participação de 3 bolsistas do Curso de Licenciatura em Artes Plásticas, do CEART/ UDESC, bem como a verba necessária para as ações de construção de material para apoio pedagógico, deslocamentos, registro fotográfico, a compra de equipamentos e produção de um vídeo, que faz parte das ações de continuidade do projeto.

Com o vídeo, o Núcleo de Arte-Educação se propõe a sensibilizar as instituições educacionais para parcerias no sentido de facilitar e promover o acesso dos estudantes de escolas públicas aos ambientes culturais, como forma de política educacional. Outro aspecto de continuidade da relação entre escola e museu é a etapa de formação de professores, para que esta relação seja cada vez mais interligada e possa construir novas formas de mutuamente, desenvolver práticas em arte e educação, que contribuam para a construção de identidades culturais, para o acesso ao patrimônio artístico e cultural público e para a construção da cidadania.

\section{Princípios Metodológicos do Projeto "O Museu a Escola"}

Em tese, pensávamos que a arte-educação desenvolvida em instituições de caráter diferenciado atendiam o mesmo público, com objetivos que se interseccionam, e assim, buscávamos os possíveis pontos em comum e os pontos de diferenciação, guardadas as devidas características e compromissos de cada uma das instituições.

Qual o papel educativo do museu para a compreensão da arte? 
Qual o papel da escola na relação com as instituições culturais de caráter educativo?

Quais os pontos em comum nesta tarefa? Que contribuições podem resultar do trabalho conjunto? Que estratégias podem ser construídas para promover esta relação de modo qualitativo?

Esta característica da problemática justifica a escolha da pesquisa-ação, enquanto estratégia de conhecimento e método de investigação concreta. Apoiamo-nos em Thiollent, 2000, "Na concepção da pesquisa-ação há um reconhecimento do papel ativo dos observadores na situação investigada e dos membros representativos desta situação."

Isto, entretanto, não retira a pesquisa-ação do âmbito científico da pesquisa social, como também se apropria de instrumentais metodológicos da pesquisa tradicional, principalmente para conhecer mais profundamente a realidade social, abrindo espaço para procedimentos de argumentação e interpretação, com base na discussão coletiva, que entendemos coerentes com a concepção dialógica da educação e as teorias de aprendizagem construtivistas.

\section{Caracterização do Projeto}

Este Projeto foi caracterizado como projeto piloto de pesquisa-ação cultural, que se propunha desenvolver ações educativas, construindo uma relação de diálogo e intervenções refletidas em conjunto entre educadores do museu e escolas envolvidas, através dos professores e equipe técnicapedagógica, visando uma ação conjunta e sistemática, desempenhando um papel educativo com bases regulares, que possam ser incluídos numa política educacional, dentro e fora do museu.

Optamos por três turmas de terceira série do ensino fundamental de três escolas públicas de 
Florianópolis, escolhidas em regiões sócio-culturais diferenciadas, quais sejam: meios rural, litorâneo e urbano.

Quando escolhemos regiões sócio- econômicas culturais diversas queríamos tentar perceber as experiências diferenciadas de vida e oportunidades refletindo-se no trabalho, nas leituras de imagens, na manifestação da experiência estética dos grupos, nas expectativas dos pais e no compromisso das escolas.

Num primeiro momento, iniciamos o mapeamento do perfil sócio-economico cultural de cada criança e a caracterização das turmas. Nesta etapa da ação da pesquisa fizemos uso de questionários, com perguntas abertas e fechadas, como instrumento de investigação.

Estes questionários foram aplicados da mesma forma nas turmas e divididos em duas partes, tendo como sujeitos da pesquisa as crianças e suas famílias. A parte que tratava das práticas culturais foi respondida pelas crianças na sala de aula, com orientação dos alunos bolsistas, que explicaram também aos estudantes como os pais deveriam responder em casa a outra parte, pois exigia dados que necessitavam da sua colaboração. O retorno foi de 80\%, no menor dos casos, média considerada por nós como participação excelente, para os primeiros contatos com as famílias das crianças envolvidas.

Isto nos levou a uma caracterização de cada turma, proporcionando-nos conhecer melhor a realidade de que tratávamos.

A escola A, aqui representada pelo meio rural, é na sua grande maioria formada por filhos de famílias de outras regiões do estado ou do país, que possuem o menor índice de escolaridade e, em termos gerais, de menor poder aquisitivo, com os pais atuando em 
diversas profissões, predominando entre os homens, o trabalho na construção civil.

Este lugar, situado entre o mar e a montanha, até há pouco tempo era caracteristicamente rural, uma região de sítios e fica numa parte da llha de grande exploração imobiliária, e que, possivelmente, atraiu um número de trabalhadores de outras regiões, muitas vezes saídos do meio rural.

A escola $B$, da região litorânea, originalmente formada por uma comunidade de pescadores, é uma das últimas regiões que mantém a pesca tradicional, mesmo que já convivendo com moradores de outros lugares, com outras profissões, sendo ainda a maioria das famílias das crianças envolvidas, nascidas e criadas naquela região, caracterizando-se por ser uma área de forte tradição da cultura da ilha, de origem açoriana.

A escola $\mathrm{C}$, representando a região urbana, é a maior escola pública estadual de Santa Catarina, que ministra do ensino infantil ao ensino médio, sendo por isso muito valorizada por parte das famílias, com procura bem maior que o número de vagas oferecidas. Por seu status congrega estudantes de diferentes lugares da região, muitas vezes distantes, formando um perfil sócioeconomico mais heterogêneo do que as outras turmas, tanto em relação à escolaridade das famílias de origem, como quanto à renda mensal familiar e à diversidade de profissões, mesmo verificando-se um predomínio de funcionários públicos, e o maior índice de mães de família que não trabalham fora de casa, representando famílias de padrão médio tradicional.

A professora da escola B é a única do grupo que tem formação em artes, e esta turma trocou várias vezes de professor de sala ao longo do ano de 2000, não tendo havido denvolvimento destes professores mais efetivamente. Os alunos formam a menor turma, sendo muito interessados e tendo um comportamento calmo, de atenção e respeito. 
Na escola A, a professora da turma, com formação em história, foi quem tomou parte da equipe do projeto, sendo esta a turma que aparentemente, apresentava maior dificuldade de concentração e de adaptação ao ambiente museológico, isto é, comportavam-se como no recreio da escola, correndo, curiosos com o espaço arquitetônico em geral, sempre querendo ver o que havia atrás das cortinas ou das falsas paredes, usadas como divisórias do espaço. Gostam muito da hora do lanche e percebíamos que para muitos este era diferenciado no dia da visita. Esta turma exigiu de nós, equipe do museu, um contínuo exercício de reflexão e debate para não cairmos no lugar comum de discriminá-los ou estigmatizá-los. Podemos aos poucos perceber com a ajuda da professora que essa era a situação da turma na escola.

A escola C, começou sendo acompanhada pela professora da sala, formada em Pedagogia.

Formavam uma turma heterogênea, com muitas crianças bastante interessadas, que muitas vezes nos surpreendiam no repertório e na capacidade de fazer relações amplas e complexas, entre os conteúdos proporcionados pelo debate das obras expostas, demonstrando possuir um capital cultural maior que a média de todos os outros estudantes da turma e do projeto, por terem acesso a informática, a cursos extraclasses, viagens. Esta realidade observada também foi motivo de debate entre a equipe, para que não fosse considerada um padrão, já que a pesquisa propunha um olhar sensível e não dogmático de avaliação comparativa.

Durante o ano de 2000, estas três turmas participaram de todas as exposições do MASC, conheceram seu acervo não só em situação de exposição, como tiveram acesso ao espaço onde as obras são armazenadas, "o guarda-roupa dos quadros" como uma criança se referiu mais tarde e às oficinas 
de manutenção e restauro, "hospital das obras" como chamaram. Por ocasião das exposições, fazíamos sempre leituras sistemáticas de algumas obras e as contextualizávamos, tanto historicamente como em relação ao cotidiano do aluno.

\section{Situaçäo Atual e Desdobramentos}

Neste ano de 2001 houve algumas modificações na equipe, tanto por parte dos professores como da equipe do Núcleo de Arte-Educação do MASC, havendo pouca mudança no grupo de crianças que participaram no ano anterior.

Neste ponto do trabalho, mesmo não concluído, já acontecem alguns desdobramentos e reflexos significativos para avaliação qualitativa, pelo próprio dinamismo que caracteriza o projeto, construído ao longo de uma relação baseada nos atos de refletir e considerar as ações de todos os envolvidos, em constante auto-avaliação. Com a mudança do ano letivo, as crianças frequentam agora a quarta série.

Neste ano, além das reuniões mensais de toda a equipe que compõe o projeto, está acontecendo um grupo de estudos, a pedido dos professores no último encontro de avaliação do ano anterior, o que consideramos um ponto de avaliação muito positivo.

$\mathrm{Na}$ escola $\mathrm{A}$, a turma pouco se alterou, mantendo-se a mesma professora de artes, proporcionando para nossa avaliação uma visibilidade do processo de mudança da professora, que mostrase cada vez mais segura e confiante, desenvolvendo o seu trabalho com arte na escola, com propostas interessantes e criativas, desprendendo-se do compromisso com datas comemorativas, trabalhando com projetos de longo prazo e deixando de preocuparse com a necessidade de apresentar diversidade de 
técnicas e modelos que caracterizava sua prática como professora. Segundo seu depoimento, ficou mais "calma" na exigência com os prazos e os resultados do trabalho final de seus alunos, expressando-se assim para descrever sua própria mudança educativa.

A escola B, no ano anterior tinha sido motivo de debates pela característica da turma e de grande satisfação pela participação entusiasta da professora, foi ela quem primeiramente começou a relatar transformações na sua relação com os alunos e na sua prática pedagógica, e mais claramente nos demonstrava mudanças; neste ano, afastou-se da escola e a turma foi dividida, por ser considerada dificil
e problemática.

A participação desta turma no projeto ficou restrita à vinda ao museu, acompanhada da professora do ano anterior e de alguma representante da escola, sem que essa participe das outras ações, como as reuniões da equipe e grupo de estudo. A professora do ano anterior, por vontade própria, no seu dia de folga, uma vez por mês acompanha esta turma e continua participando das reuniões e demais ações do projeto.

O comportamento destas crianças regrediu, elas voltaram a ser desinteressadas e desatentas, aproveitando o espaço do museu, muitas vezes, para apresentar um comportamento de resistência.

Na escola $\mathrm{C}$ houve mudança de professor, mas a turma se manteve igual, contrariando uma prática histórica da instituição, de alterar a composição das turmas na quarta série. Esta prática foi comunicada pela equipe pedagógica para a equipe do MASC nas reuniões de negociação que mantivemos com cada uma das escolas, após apresentarmos o projeto e formalizarmos o convite para a formação da equipe das escolas que formariam o piloto desta pesquisa. 
Isso foi objeto de debate entre a equipe do museu, tendo sido motivo de se cogitar a busca de outra escola, mas acabamos por optar trabalhar com esta realidade como uma variável, tendo pesado na escolha a tradição desta escola, que nos quatro primeiros anos do fundamental, caracteriza-se como colégio de aplicação, possuindo o curso médio de formação de professor.

Para nossa surpresa e satisfação, ao contactarmos com a escola para recomeçarmos em fevereiro deste ano, soubemos que a turma permaneceria a mesma, a pedido dos pais, os quais manifestaram fortemente o desejo de que seus filhos continuassem a freqüentar o museu.

Esta escola designou uma nova professora, em função de sua vontade de participar do projeto. Vale ainda destacar que, a professora do ano anterior participa das reuniões, isto é, continua sendo parte da equipe, voluntariamente. As crianças vem freqüentando o MASC com interesse cada vez maior, demonstrando familiaridade com espaços culturais. Por ocasião de uma pesquisa como tarefa escolar, foram em busca do assunto em outros museus da cidade, procuraram uma artista que estava expondo no museu, telefonaram e alguns foram até seu espaço/ atelier para saber mais sobre o seu trabalho.

\section{Considerações Finais}

As imagens captadas para a produção do vídeo, no qual paralelamente trabalhamos, escrevendo o roteiro, escolhendo imagens, têm sido para a equipe do MASC, um recurso a mais de avaliação, tanto na observação das imagens como nos relatos que temos gravado com os professores e com quase todo o universo de crianças envolvidas.

A política da atual administração do MASC, em todas as exposições temporárias, tem reservado um 
espaço de mostra para artistas residentes e atuantes no Estado, afinados com a linguagem contemporânea. Isso tem nos oportunizado muitas vezes levar o artista ao museu, durante as visitas das crianças às exposições, resultando numa experiência rica para as crianças, e para os artistas, que atualmente observam com surpresa a afinidade dessas crianças com o espaço museológico e a apreciação e interpretação
que fazem das obras.

No processo, temos tido a oportunidade de confirmar nossas expectativas de que o trabalho pedagógico necessita de um profundo envolvimento com a vida, precisa ter sentido, ser significativo e prazeroso para todos os envolvidos no processo, dialeticamente com a exigência da sistematização constante e de espírito investigativo, do esforço exigido pela prática travada nas relações humanas com o conhecimento, com as trocas contínuas da relação ensino e aprendizagem.

Entendemos que esta característica do trabalho pedagógico afina-se muito bem com a manifestação humana de dar forma a idéias e pensamentos, transformando a matéria para se comunicar de forma

Como coordenadora deste projeto posso afirmar que esta experiência tem proporcionado uma grande riqueza para minha vida profissional e pessoal, e a confirmação da minha crença na educação em arte. Posso esperar que este trabalho se diversifique em qualidade e quantidade de pessoas com acesso à arte como patrimônio público, sem deixar de registrar o desprezo com que é muitas vezes tratada esta área de conhecimento, por aqueles que possuem o poder político e econômico, o que dificulta a concretização de outras tantas experiências como esta. 


\section{Reterências Bibliográficas}

BARBOSA, Ana Mae. A imagem no ensino da arte: anos oitenta e novos tempos. São Paulo: Perspectiva; 1991.

Arte - Educação:

leitura no subsolo. São Paulo: Cortez, 1997.

BELLONI, Maria Luiza. Escola versus televisão: uma questão de linguagem. Educação e Sociedade, ano XVI. N 52; dezembro.1995.

DURAN, José Carlos. Arte, Privilégio e Distinção: artes plásticas, arquitetura e classe dirigente no Brasil, 1885/1985. São Paulo, 1989.

FUSARI, Maria F. de Resende e C. Ferraz. Arte na educação escolar. São Paulo: Cortez,1993.

FERRAZ, Maria Heloisa C. de T. Maria F. de Rezende e Fusari. Metodologia da educação artística. São Paulo: Cortez, 1993.

MARTINS, Míriam Celeste Ferreira Dias. Didática do ensino da arte: poetizar, fruir e conhecer arte. São Paulo: FTD, 1998.

OSTROWER, Fayga. Universos da arte. Rio de Janeiro: Imago, 1997.

PEREGRINO, Yara Rosas (org) Da camiseta ao museu: o ensino das artes na democratização da cultura. João Pessoa: Editora universitária, 1995. PILLAR, Analice. O vídeo e a metodologia triangular no ensino da arte. Porto Alegre: UFRGS, Fundação TOCHPE, 1992.

PORCHER, Louis (org). Educação artística: luxo ou necessidade? São Paulo: Cortez, 1990.

THIOLLENT, Michel. Metodologia da PesquisaAção. São Paulo: Cortez, 2000.

HERNÁNDEZ, Fernando. Cultura Visual, Mudança Educativa e Projeto de trabalho. Porto Alegre: Artes Médicas Sul, 2000. 